\title{
O Brasil no contexto de controle de qualidade de plantas medicinais
}

\author{
Tatiana M. Souza-Moreira, Hérida R. N. Salgado, Rosemeire C. L. R. Pietro*
}

\author{
Departamento de Fármacos e Medicamentos, Pós-graduação em Ciências Farmacêuticas, Faculdade de Ciências \\ Farmacêuticas, Universidade Estadual Paulista "Júlio de Mesquita Filho", Rodovia Araraquara-Jaú, km 1, \\ 14801-902 Araraquara-SP, Brasil.
}

\begin{abstract}
RESUMO: Atualmente, as plantas medicinais movem altos valores financeiros em todo o mundo e representam o tipo de tratamento mais acessível para cerca de $80 \%$ da população, principalmente entre os países em desenvolvimento. Entretanto, existe ainda uma falta de conhecimento sobre propriedades químicas, farmacológicas e toxicológicas a fim de assegurar a eficácia e segurança das plantas medicinais. Os critérios de eficácia e segurança de plantas medicinais estão relacionados a qualidade, isto é, as plantas necessitam ser corretamente identificadas, cultivadas e coletadas, devem estar livres de material estranho, partes de outras plantas e contaminações inorgânicas e/ ou microbianas. O objetivo deste estudo foi o de elucidar os diferentes processos e padronizações sobre o controle de drogas vegetais, principalmente no Brasil.
\end{abstract}

Unitermos: Plantas medicinais, fitoquímica, controle de qualidade.

\begin{abstract}
Brazil in the context of plants and derivates quality control". Nowadays medicinal plants move high financial values at the world and represent a type of treatment more accessible for about $80 \%$ of people, mainly among developing countries. However, there is a lack of knowledge about chemical, pharmacological and toxicological properties towards ensure their efficacy and safety. Efficacy and safety criteria of medicinal plants are related to quality, that is, the plants need to be correctly identified, cultivated and harvested, they must be free of strange material, part of other plants and inorganic and/or microorganisms contamination. The aim of this study was to elucidate different process and standardizations about quality control of vegetal drugs mainly in Brazil.
\end{abstract}

Keywords: Medicinal plants; phytochemistry; quality control.

\section{INTRODUÇÃO}

Por longos períodos na história, o uso de plantas medicinais foi presente não só devido ao seu caráter alimentar, mas também às suas propriedades de cura, sejam elas reais ou ritualísticas. Entretanto, até a metade do século XX, o uso de medicamentos de origem sintética tornou-se mais amplo que o uso de plantas medicinais, principalmente na sociedade ocidental, com destaque para os países desenvolvidos visto que os considerados países em desenvolvimento permaneceram fazendo uso das propriedades curativas das plantas, certamente devido às difíceis condições econômicas de aquisição dos medicamentos sintéticos (Korolkovas, 1996; Farnsworth, 1997; Rates, 2001; Springfield et al., 2005; Foglio et al., 2006; Gupta et al., 2008). A Organização Mundial da Saúde (OMS) estimou que $80 \%$ da população dependam da medicina tradicional (Springfield et al., 2005). A cultura do uso de plantas e de outras fontes naturais com propriedades terapêuticas vem sendo valorizada pela sociedade do mundo inteiro e retornou ao status de uma fonte de produtos medicinais devido à busca por hábitos mais saudáveis de vida e pelo difícil tratamento de certas doenças e resistência microbiana (De Smet, 2004; Giveon et al., 2004; Rocha et al., 2004; Bugno et al., 2005).

NoBrasil, afitoterapiaéuma opçãomedicamentosa que se adequa às necessidades de vários municípios no atendimento primário à saúde (Eldin \& Dunford, 2001). De forma geral, os fatores da expansão da fitoterapia devem-se aos efeitos adversos de fármacos sintéticos, à preferência dos consumidores por tratamentos "naturais", crescente validação científica das propriedades farmacológicas de espécies vegetais, desenvolvimento de novos métodos analíticos para o controle de qualidade, desenvolvimento de novas formas de preparações e administração dos produtos e relativo baixo custo (Cañigueral et al., 2003; Melo et al., 2007).

Uma abordagem dos guias e das técnicas de controle de qualidade de drogas vegetais e produtos fitoterápicos, com ênfase sobre o Brasil, é apresentada neste trabalho de forma a comparar procedimentos e legislações existentes. 


\section{CONTROLE DE QUALIDADE E LEGISLAÇÃO}

Muitas das preparações que utilizam plantas medicinais ainda necessitam de estudos científicos mais detalhados, incluindo padronização química, testes biológicos in vitro e em modelos animais e avaliação clínica. Para a etapa de avaliação clínica, o controle de qualidade passa a ser uma prática totalmente indispensável. Métodos de controle de qualidade de algumas plantas medicinais já validados estão presentes em monografias encontradas, por exemplo, na Farmacopéia dos Estados Unidos, Farmacopéia Chinesa, monografias da OMS, Farmacopéia Japonesa e Farmacopéia Brasileira, que por sua vez, inclui 44 monografias de plantas medicinais na sua maioria não nativas do Brasil (Ong, 2004; Brandão et al., 2006).

No Brasil, em 2004, foi aprovada a Resolução $\mathrm{n}^{\mathrm{o}} 48$, que dispõe sobre o registro de medicamentos fitoterápicos e, entre outros pontos, abrange as etapas de controle de qualidade da droga vegetal, do produto acabado e da importação de produtos fitoterápicos (Anvisa, 2004).

Em 1998, a Organização Mundial da Saúde reuniu procedimentos no documento Quality control methods for medicinal plant materials, que podem ser tomados como base para que auxiliem as nações, a partir de sua legislação, formar padrões de controle de qualidade de drogas vegetais e produtos (WHO, 1998). Em 2005 houve revisão do guia com adequação para a detecção e quantificação de alguns contaminantes e resíduos em plantas medicinais (WHO, 2005). No Brasil, a quarta edição da Farmacopéia (1988), junto com outras literaturas não oficiais, como o livro organizado por Simões et al (2004), contêm parâmetros semelhantes aos da OMS para verificação da identidade e controle de qualidade de drogas vegetais. Uma comparação entre estes procedimentos pode ser verificada na Tabela 1 .

O Decreto $\mathrm{n}^{\mathrm{0}} 5.813$, de 22 de junho de 2006, sobre a Política Nacional de Plantas Medicinais e Fitoterápicos, tem como algumas de suas diretrizes garantir e promover a segurança, a eficácia e a qualidade no acesso a plantas medicinais e fitoterápicos, promover e reconhecer as práticas populares de uso de plantas medicinais e remédios caseiros e promover a adoção de boas práticas de cultivo e manipulação de plantas medicinais e de manipulação e produção de fitoterápicos, a partir de uma legislação específica.

\section{TÉCNICAS DE CONTROLE DE QUALIDADE}

É possível observar que ainda existe resistência dos profissionais prescritores quanto ao uso de fitoterápicos, o que pode ser explicado pela origem extrativa da maioria das plantas medicinais comercializadas no Brasil, seja da Mata Atlântica, Amazônia, Caatinga ou Cerrado, levando a problemas de risco de extinção da espécie e sustentabilidade, bem como de fraude e contaminação do material. Com a finalidade de aumentar o rendimento do
Tabela 1. Comparação entre os procedimentos da OMS e Farmacopéia Brasileira.

\begin{tabular}{|c|c|c|}
\hline Procedimento & $\begin{array}{l}\text { OMS } \\
(1998)\end{array}$ & $\begin{array}{l}\text { F. Bras. } \\
(1988)\end{array}$ \\
\hline Amostragem & $\mathrm{x}$ & $\mathrm{x}$ \\
\hline Determinação de material estranho & $\mathrm{x}$ & $\mathrm{x}$ \\
\hline Verificação macro e microscópica & $\mathrm{x}$ & \\
\hline $\mathrm{CCD}$ & $\mathrm{x}$ & \\
\hline Determinação de cinzas totais & $\mathrm{x}$ & $\mathrm{x}$ \\
\hline Determinação de cinzas insolúveis em ácido & & $\mathrm{x}$ \\
\hline Determinação de extrativos & $\mathrm{x}$ & \\
\hline Determinação de água & $\mathrm{x}$ & $\mathrm{x}$ \\
\hline Determinação de óleos voláteis & $\mathrm{x}$ & $\mathrm{x}$ \\
\hline Determinação de óleos fixos & & $\mathrm{x}$ \\
\hline Determinação do cineal & & $\mathrm{x}$ \\
\hline Determinação do amargor & $\mathrm{x}$ & \\
\hline Determinação da atividade hemolítica & $\mathrm{x}$ & \\
\hline Determinação de taninos & $\mathrm{x}$ & \\
\hline Determinação do índice de inchamento & $\mathrm{x}$ & \\
\hline Determinação do índice de espuma & $\mathrm{x}$ & $\mathrm{x}$ \\
\hline $\begin{array}{l}\text { Determinação de substâncias extraíveis por } \\
\text { álcool }\end{array}$ & & $\mathrm{x}$ \\
\hline Determinação do resíduo de pesticidas & $\mathrm{x}$ & \\
\hline Determinação de arsênico e metais pesados & $\mathrm{x}$ & \\
\hline $\begin{array}{l}\text { Determinação de microrganismos (e } \\
\text { aflatoxinas) }\end{array}$ & $\mathrm{x}$ & \\
\hline Contaminação radioativa & $\mathrm{x}$ & \\
\hline Determinação de resíduos de pesticidas & $\mathrm{x}$ & \\
\hline Determinação de arsênico e metais tóxicos & $\mathrm{x}$ & \\
\hline
\end{tabular}

produto a ser vendido ou até mesmo por falta de cuidados na coleta e falta de tratamento do material coletado, é relativamente freqüente a presença de materiais estranhos e a de outras plantas contaminantes, troca de uma espécie por outra e presença de fungos e bactérias, principalmente, coliformes fecais. Uma provável causa da falta de confiança desses profissionais nesse tipo de produto também se deve à falta de padronização dos extratos, que podem conter ou não o princípio ativo ou compostos tóxicos em quantidade adequada dependendo do plantio e da época do ano, interferindo na reprodutibilidade dos fitoterápicos. É reconhecido que dados de eficácia e segurança de várias plantas medicinais ainda não são suficientes para dar suporte ao seu uso, por vezes devido à falta de metodologias adequadas de avaliação dessas plantas. E, em se tratando da composição, muitas vezes não se tem estabelecido o princípio ativo ou tóxico, sua concentração e seu conhecimento farmacológico e toxicológico (Barata, 2005; Springfield et al., 2005).

A busca por marcadores baseia-se na suposição de que qualquer planta possui um ou poucos constituintes responsáveis por sua atividade e que, portanto, substituiriam o uso da planta na sua totalidade permitindo doseamentos precisos e determinação das variações de bioatividade 
(Phillipson, 1995). Contudo, vários são os exemplos de que a bioatividade pode ser o resultado do sinergismo entre os constituintes de uma determinada planta. Já foram relatados casos de constituintes tidos como ativos que, quando isolados, apresentaram-se tóxicos para uso humano ou com solubilidade limitada (Liang et al., 2004; Springfield et al., 2005).

Visando diminuir a resistência da prescrição de fitoterápicos, e com a finalidade de aumentar a possibilidade de adesão da população ao tratamento, é de extrema importância, não só o controle de qualidade desde o cultivo da droga vegetal até o produto final, mas também o estudo fitoquímico das plantas, farmacológico e toxicológico (Melo et al., 2007).

Deve-se ter em mente que o uso de matéria vegetal falsificada pode ocorrer pela variedade de nomenclaturas populares para diferentes espécies. Desta forma, é importante o conhecimento da espécie correta pelo seu nome científico pelos coletores e distribuidores do material, além da existência de técnicas padrão que confirmem a identidade da amostra (Duarte \& Bardal, 2002; Alves et al., 2007). O primeiro passo de identificação de uma espécie vegetal pode ser feito pelas suas características morfohisto-anatômicas, macro e microscopicamente (Duarte \& Menarim, 2006).

\section{PROCEDIMENTOS DE CONTROLE CONSTITUIÇÃO QUÍMICA}

DA

O emprego de técnicas cromatográficas e analíticas que permitam a separação e o isolamento de substâncias de um extrativo vegetal mostra-se necessário tanto para o conhecimento da composição química, do princípio ativo e/ou do composto tóxico de uma planta, como também para a determinação de uma substância, ou grupo de substâncias, que sirva como marcadora daquela espécie, para controle qualitativo e quantitativo da droga, propiciando a padronização do material vegetal e produtos relacionados (Drasara \& Moravcova, 2004; Famei et al., 2006; Liu et al., 2007). Mais do que rapidez, alta sensibilidade e seletividade são as grandes vantagens dessas técnicas, sendo que o perfil de uma planta traçado pelo uso da cromatografia líquida de alta eficiência (CLAE), por exemplo, pode proporcionar a identificação da presença dos marcadores e também de outros compostos, oferecendo uma caracterização completa da planta ou do produto analisado além de permitir a distinção entre espécies próximas (Drasara \& Moravcova, 2004; Liu et al., 2007). Métodos simples e rápidos de análise são as melhores opções para serem utilizados em laboratórios de regulamentação e laboratórios de controle de qualidade de produtos a base de material vegetal (Drasara \& Moravcova, 2004).

Alguns desafios para o desenvolvimento de um método analítico a ser utilizado no estudo de materiais vegetais são: 1) extração dos constituintes, principalmente compostos ativos, a partir de uma matriz complexa; 2) estabilidade térmica e sob luz; 3) falta de substâncias de referência; 4) variação da composição química entre lote coletado, localidade e época do ano (Drasara \& Moravcova, 2004; Blank et al., 2007).

Métodos mais modernos como extração por fluido supercrítico, por líquido pressurizado e destilação por microondas propiciam melhor extração, redução do consumo de solventes orgânicos, da degradação da amostra e dos passos de purificação (Drasara \& Moravcova, 2004; Deng et al., 2007). A determinação da constituição química da amostra pode ser feita por diferentes técnicas cromatográficas: cromatografia em camada delgada (CCD), cromatografia líquida de alta eficiência (CLAE), cromatografia gasosa (CG) e eletroforese capilar (EC) (Liang et al., 2004).

A CCD é o método mais comum de análise, principalmente antes da implementação dos métodos de CLAE e CG, por ser fácil, versátil, rápido e sensível para uma caracterização prévia dos constituintes de uma droga vegetal, proporcionando análise qualitativa $\mathrm{e}$ semi-quantitativa, indicando uma possível adulteração (Mukherjee, 2002; Famei et al., 2006). O método de CG torna mais precisa a identificação de compostos voláteis, permite a quantificação e a verificação de mudanças na composição do óleo essencial, que podem ser causadas por oxidação, ação de enzimas ou fermentação microbiana, levando a compostos sem atividades ou tóxicos (Liang et al., 2004). A técnica de CLAE apresenta-se com relativa facilidade de manipulação e permite ampla análise de diferentes compostos. A análise por CLAE deve considerar a necessidade de condições ótimas de separação, o que depende da fase móvel utilizada, $\mathrm{pH}$, pressão da bomba, preparo da amostra etc (Sanyal et al., 2003; Thanawiroon \& Linhardt, 2003; Liang et al., 2004).

O acoplamento de técnicas cromatográficas, ou técnicas cromatográficas hifenadas, vem sendo mais uma importante ferramenta para identificação dos constituintes das plantas e análise de sua qualidade. No acoplamento destas técnicas, faz-se uso de métodos eficientes de separação, como CLAE e CG, com técnicas espectrométricas que funcionam para detecção, como espectrofotometria de UV-Visível (DAD), espectrometria de massas (MS e MS-MS) e ressonância magnética nuclear (RMN), fornecendo informações adicionais sobre a estrutura química dos componentes da amostra. Os instrumentos quando acoplados promovem melhores resultados por se eliminar a interferência de instrumentos, por apresentar seletividade, capacidade de separação cromatográfica e precisão de resultados (Mukherjee, 2002; Liang et al., 2004).

Embora a CLAE seja aplicada à grande maioria das drogas e dos produtos vegetais, foi observado que alguns produtos originados da medicina alternativa não se adequam a essas técnicas por serem constituídos por uma variedade de princípios ativos, dificultando seu processo 
de controle de qualidade. Nesses casos, alguns autores propõem métodos biológicos para análise destas plantas e suas preparações (Huang et al., 2004; Rong et al., 2007).

Biocromatografia molecular é um método tido como efetivo para análise de compostos biologicamente ativos baseando-se em interações entre os compostos e proteínas, enzimas ou anticorpos imobilizados, o que colabora também para a avaliação do tipo de ligação entre proteína e composto ativo (Noctor et al., 1992; Huang et al., 2004).

Rong e colaboradores (2007) realizaram estudos de testes biológicos de controle de qualidade baseados em resposta genômica de expressão up e down de genes marcadores definidos utilizando as técnicas de microarray para selecionar o perfil de transcrição ou de PCR em tempo real de RNA (qRT-PCR) para quantificação após exposição ao produto vegetal.

\section{PROCEDIMENTOS DE CONTROLE MICROBIOLÓGICO}

O controle de qualidade microbiológico de plantas medicinais e/ou fitoterápicos deve considerar que, pela origem, os produtos vegetais estão em contato direto com o ambiente e, portanto, com o solo rico em esporos de fungos, patas de insetos e animais carregadas de bactérias e esporos (Rocha et al., 2004). A contaminação por esses microrganismos pode acarretar deterioração do material por ser fonte de enzimas e de patógenos, podendo levar ao desenvolvimento de doenças. São produtos de alto risco, sendo necessário definir medidas adequadas de controle higiênico-sanitário para garantir a qualidade e segurança deste tipo de produto desde a coleta, armazenamento e manipulação até o produto final (Kneifel et al., 2002).

No Brasil, a preocupação com a contaminação de materiais vegetais vem desde a década de 80 com estudos sobre qualidade microbiológica (Fisher et al., 1996). Na Resolução $n^{\circ}$ 481, de 23 de setembro de 1999, está estabelecido parâmetros de controle microbiológico para os produtos de higiene pessoal, cosméticos e perfumes, que também preconizou os limites de contaminação microbiana para materiais vegetais, sendo considerados para controle de qualidade microbiológico como medicamentos nãoestéreis.

\section{CONCLUSÕES}

O uso das plantas medicinais representa uma fonte de acesso em potencial para as camadas mais carentes da sociedade e também possibilita a descoberta de novas moléculas ou de novos tratamentos de doenças que apresentem tratamento e/ou prognóstico difíceis (Rates, 2001).

Entretanto, assim como qualquer outro medicamento, aqueles baseados em plantas devem comprovar sua eficácia e segurança para uso, exigindo que procedimentos de controle de qualidade sejam estabelecidos em toda a sua cadeia produtiva, desde o seu plantio até a droga vegetal ou fitoterápico prontos para dispensação.

É necessária a determinação da maioria dos constituintes químicos de uma planta para que sejam asseguradas a confiabilidade e repetibilidade dos dados clínicos e farmacológicos, conhecer quais são os compostos ativos e possíveis efeitos adversos, a fim de promover a manutenção da qualidade do material. Para o controle de qualidade desse material vegetal, não só metodologias químicas devem ser aplicadas, mas também botânicas para identificação da espécie, análise de fraudes e de contaminações grosseiras além de metodologias de controle de qualidade microbiológico, analisando a contaminação por microrganismos que podem ser patogênicos para o usuário ou que podem propiciar a degradação do material vegetal diminuindo, assim, a sua eficácia e segurança.

\section{REFERÊNCIAS BIBLIOGRÁFICAS}

Alves TMA, Marengo S, Machado C, Caldeira R, Carvalho O, Isaias RMS, Stehmann JR, Zani C 2007. Morphological, anatomical, macro and micromolecular markers for Solanum cernuum identification. Rev Bras Farmacogn 17: $542-548$.

Anvisa 1999 Resolução n ${ }^{\circ}$ 481, de 23 de setembro de 1999. Estabelece os parâmetros de controle microbiológico para os produtos de higiene pessoal, cosméticos e perfumes conforme o anexo desta resolução. Diário Oficial da União, Disponível em: http://e-legis.bvs.br/ leisref/public/showAct.php?id=259. Acesso em: $26 \mathrm{de}$ jul. de 2007.

Anvisa 2004. Resolução RDC n 48, de 16 de março de 2004. Dispõe sobre o registro de medicamentos fitoterápicos. Diário Oficial da União. Disponível em http://e-legis. anvisa.gov.br/leisref/public/showAct.php?id=10230, acesso em setembro de 2007.

Barata L 2005. Empirismo e ciência: fonte de novos fitomedicamentos. Cien Cultura 57: 4-5.

Blank AF, Costa AG, Arrigoni-Blank MF, Cavalcanti SCH, Alves PB, Innecco R, Ehlert PAD, Sousa IF 2007. Influence of season, harvest time and drying on Java citronella (Cymbopogon winterianus Jowitt) volatile oil. Rev Bras Farmacogn 17: 557-564.

Bugno A, Buzzo AA, Nakamura CT, Pereira TC, Matos D, Pinto TJA 2005. Avaliação da contaminação microbiana em drogas vegetais. Rev Bras Cien Farmac 41: 491-497.

Brandão MGL, Cosenza GP, Moreira RA, Monte-Mor RLM 2006. Medicinal plants and other botanical products from the Brazilian Official Pharmacopoeia. Rev Bras Farmacogn 16: 408-420

Cañigueral S, Dellacassa E, Bandoni AL 2003. Plantas Medicinales y Fitoterapia: ¿indicadores de dependencia o factores de desarrollo? Acta Farm Bonaerense 22: 265278. 
Decreto $\mathrm{n}^{\mathrm{o}} 5.813$, de 22 de junho de 2006. Aprova a política nacional de plantas medicinais e fitoterápicos e dá outras providências. Diário Oficial da União, Brasília, 2006. http://www.mda.gov.br/saf/arquivos/0950311774.doc, acesso em julho de 2007.

De Smet PAGM 2004. Health risks of herbal remedies: an update. Clin Pharmacol Ther 76: 1-17.

Deng C, Liu N, Gao M, Zhang X 2007. Recent developments in sample preparation techniques for chromatography analysis of traditional chinese medicines. J Chromatogr A 1153: 90-96.

Drasara P, Moravcova J 2004. Recent advances in analysis of Chinese medical plants and traditional medicines. $J$ Chromatogr B 812: 3-21.

Duarte MR, Bardal D 2002. Qualidade de amostras de fármacos vegetais comercializados em Curitiba - PR. Visão Acadêmica 3: 65-68.

Duarte MR, Menarim DO 2006. Morfodiagnose da anatomia foliar e caulinar de Camellia sinensis (L.) Kuntze, Theaceae. Rev Bras Farmacogn 16: 545-551.

Eldin S, Dunford A 2001. Fitoterapia na atenção primária à saúde. São Paulo: Manole.

Famei L, Zhili X, Xiumei L, Feng Q, Xiaoqin L 2006. Strategy and chromatographic technology of quality control for traditional chinese medicines. Chin J Chromatogr 24: 537-544.

Farmacopéia Brasileira, 4. ed., 1988. São Paulo: Atheneu.

Farnsworth NR 1997. Testando plantas para novos remédios. Rio de Janeiro: Nova Fronteira.

Fischer DCH, Ohara MT, Saito T 1996. Padrão microbiano em medicamentos não estéreis de uso oral: enquadramento de produtos fitoterápicos. Rev Bras Farmacogn 5: 2954.

Foglio MA, Queiroga CL, Sousa IMO, Rodrigues RAF 2006. Plantas Medicinais como Fonte de Recursos Terapêuticos: Um Modelo Multidisciplinar. Construindo a História dos Produtos Naturais. http://www.multiciencia.unicamp.br/ art04_7.htm, acesso em setembro de 2007.

Giveon SM, Liberman N, Klang S, Kahan E 2004. Are people who use "natural drugs" aware of their potentially harmful side effects and reporting to family physician? Patient Educ Couns 53: 5-11.

Gupta D, Bleakley B, Gupta RK 2008. Dragon's blood: Botany, chemistry and therapeutic uses. $J$ Ethnopharmacol 115 : 361-380.

Huang X, Kong L, Li X, Chen X, Guol M, Zou H 2004. Strategy for analysis and screening of bioactive compounds in traditional Chinese medicines. J Chromatogr B 812: 7184.

Kneifel W, Czech E, Kopp B 2002. Microbial contamination of medicinal plants - a review. Planta Med 68: 5-15.

Korolkovas A 1996. A riqueza potencial de nossa flora. Rev Bras Farmacogn 1: 1-7.

Liang Y, Xie P, Chan K 2004. Quality control of herbal medicines. J Chromatogr B 812, 53-70.

Liu M, Li Y, Chou G, Cheng X, Zhang M, Wang Z 2007.
Extraction and ultra-performance liquid chromatography of hydrophilic and lipophilic bioactive components in a Chinese herb Radix Salviae Miltiorrhizae. J Chromatogr A 1157: 51-55.

Melo JG, Martins JDGR, Amorim ELC, Albuquerque UP 2007. Qualidade de produtos a base de plantas medicinais comercializados no Brasil: castanha-da-índia (Aesculus hippocastanum L.), capim-limão (Cymbopogon citratus (DC.) Stapf ) e centela (Centella asiatica (L.) Urban). Acta Bot Bras 21: 27-36.

Mukherjee PK 2002. Quality control of herbal drugs: an approach to evaluation of botanicals. New Delhi: Business Horizons.

Noctor TA, Wainer IW, Hage DS 1992. Allosteric and competitive displacement of drugs from human serum albumin by octanoic acid, as revealed by high-performance liquid affinity chromatography, on a human serum albuminbased stationary phase. J Chromatogr 577: 305-315.

Ong ES 2004. Extraction methods and chemical standardization of botanicals and herbal preparations. $J$ Chromatogr $B$ 812: 23-33.

Phillipson JD 1995. A matter of some sensitivity. Phytochemistry 3: 1319-1343.

Rates SMK 2001. Plants as source of drugs. Toxicon 39: 603613.

Rocha LO, Soares MMSR, Corrêa CL 2004. Análise da contaminação fúngica em amostras de Cassia acutifolia Delile (sene) e Peumus boldus (Molina) Lyons (boldo-doChile) comercializadas na cidade de Campinas, Brasil. Rev Bras Cien Farmac 40: 521-527.

Rong J, Tilton R, Shen J, Ng KM, Liu C, Tam PKH, Lau ASY, Cheng YC 2007. Genome-wide biological response fingerprinting (BioReF) of the Chinese botanical formulation ISF-1 enables the selection of multiple marker genes as a potential metric for quality control. $J$ Ethnopharmacol 113: 35-44.

Sanyal U, Bhattacharyy S, Patra A, Hazra B 2003. Liquid chromatographic separation of derivatives of diospyrin, a bioactive bisnaphthoquinonoid plant-product, and analogous naphthyl compounds. J Chromatogr A 1017: 225-232.

Simões CMO, Gosmann G, Schenkel EP 2004. Farmacognosia: da planta ao medicamento. Porto Alegre/ Florianópolis: Ed. Universidade/ UFRGS/ Ed. da UFSC.

Springfield EP, Eagles PKF, Scott G 2005. Quality assessment of South African herbal medicines by means of HPLC fingerprinting $J$ Ethnopharmacol 101: 75-83.

Thanawiroon C, Linhardt RJ 2003. Separation of a complex mixture of heparin-derived oligosaccharides using reversed-phase high-performance liquid chromatography. J Chromatogr A 1014: 215-223.

WHO 1998. Quality control methods for medicinal plant materials. http://whqlibdoc.who.int/ publications/1998/9241545100.pdf, acesso em setembro de 2007.

WHO 2005. Quality control methods for medicinal plant 
materials. Revised Draft Update. http://www. who.int/medicines/services/expertcommittees/ pharmprep/QAS05_131Rev1_QCMethods_Med_

PlantMaterialsUpdateSept05.pdf, acessada em setembro de 2007. 